\title{
Simulation to Teach Nursing Students About End-of-Life Care
}

Lisa Hjelmfors, Anna Strömberg, Katarina Karlsson, Louise Olsson and Tiny Jaarsma

\author{
Journal Article
}

\section{Tweet}

N.B.: When citing this work, cite the original article.

Original Publication:

Lisa Hjelmfors, Anna Strömberg, Katarina Karlsson, Louise Olsson and Tiny Jaarsma, Simulation to Teach Nursing Students About End-of-Life Care, Journal of Hospice and Palliative Nursing, 2016. 18(6), pp.512-518.

http://dx.doi.org/10.1097/NJH.0000000000000279

Copyright: Lippincott, Williams \& Wilkins

http://www.lww.com/

Postprint available at: Linköping University Electronic Press

http://urn.kb.se/resolve?urn=urn:nbn:se:liu:diva-133105

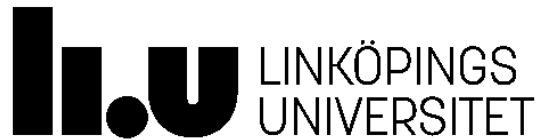




\title{
Title
}

\section{Simulation to teach nursing students about end-of-life care}

\begin{abstract}
There is minimal education on death and dying in undergraduate nursing programs, leaving the students unprepared to provide sufficient care to dying patients and their families. This paper describes a teaching innovation on how end-of-life care simulation can provide a successful and appreciated learning situation for nursing students, teaching them communication skills in challenging situations. Modifications in the setup of the simulation might help the students to focus more on communication and existential issues instead of mostly practical ones.
\end{abstract}

Keywords: End of life care education; Simulation; Undergraduate nursing students; 


\section{Introduction}

In nursing education, the development and learning of clinical skills are shifting from learning in clinical situation to learning by simulation. ${ }^{1}$ Simulation can be defined as a situation or an event which is made to resemble clinical practice to enhance student learning. In the most advanced simulations, technologically lifelike, full-body sized manikins with visible respiration, palpable pulse and vocal sounds are used to produce a high level of realism and interaction. ${ }^{2}$ The manikins are used for training basic clinical nursing skills such as for example, post-operative care, acute respiratory problems and resuscitation. ${ }^{3}$ In a simulation situation, the student can improve skills in a non-threatening environment that also provides opportunities for critical thinking, decision- making, clinical skill performance and team building. ${ }^{4}$ Students have demonstrated high levels of learner satisfaction with using high fidelity manikins as patients in simulation situations, and this might enhance the students' motivation and facilitate the learning process. ${ }^{4,5}$

There is minimal education on death and dying in many undergraduate nursing programs, often leaving the students unprepared to provide sufficient care to dying patients and their families in these difficult situations. ${ }^{6,7}$ There is also a notable lack of attention to developing nursing students' ability to communicate in a satisfying way with patients at the end-of-life, and teaching the students to truly listen to the patients 'concerns, values and goals. ${ }^{8}$ Recently, simulation has been introduced as a teaching innovation for nursing students to practice endof-life and it appears to be an attractive learning strategy. End-of-life care simulations can produce an effective and safe learning situation were the students increased their knowledge about palliative care principles and felt more comfortable and confident in communicating with patients and their families. ${ }^{1}$ In a recent review of the literature, it was described that the main positive concept in the simulation were the scenarios used in the simulations, which provided the students with a personal and realistic experience of death and dying. ${ }^{9}$ However, 
despite these positive examples, there is still little research published exploring the delivery of, and students' experiences of, such end-of-life care simulations. ${ }^{6}$

Therefore, this paper aims to increase the knowledge about end-of-life care simulation in nursing education by describing and evaluating the delivery of simulation when teaching third-year nursing students about end-of-life care.

\section{Context of the teaching innovation}

Problem-based learning (PBL) ${ }^{10,11}$ is used as the teaching method for nursing students at Linköping University. Traditional lectures are mixed with tutorial groups, each comprised of 8-9 students. Supportive learning elements are provided, such as training in "real life" situations using simulated patients and family members. Each group has their own tutor present during the preparation, simulation and debriefing sessions. The tutors are nurses, most of them are experienced in end-of-life care, and they have an important role in facilitating the learning process for the students using PBL. ${ }^{10}$ They are trained in the PBL curriculum provided by the university and they conduct practice runs of the simulation and the debriefing process. During faculty meetings that take place once a semester, they discuss learning goals, pitfalls and possibilities of the simulation with other tutors. The simulation described in this study was part of an end-of-life care simulation used during the last term of the 3- year bachelor degree level nursing education when the students learn and practice basic palliative care, something they are expected to be able to handle as nurses. 
Besides lectures on chronic illness, the students had lectures about symptom relief, good communication in challenging situations, and supportive care for for the family experience in end-of-life situation. Before the simulation sessions, the students had readings of the end-oflife care scenario. They also prepared and familiarized themselves by discussing the situation of the patient and the family in their tutorial group. The students practiced communication skills in clinical meetings with patients and family during trainee periods before the simulation takes place. At the simulation centre, the students were further informed about the simulation that would take place, they were introduced to the location of the patient and the family and the available medical equipment.

\section{Simulation procedure}

At the clinical simulation center, the tutorial group was faced with three scenarios that all took place during the same day. These were presented to the students as taking place during one week in the patient's life, on day 1, 3 and 7. The simulation procedure ended with a postsimulation debriefing.

\section{Scenario 1}

A high fidelity manikin played the patient, a 40-year-old woman named Karin who was dying from cancer. The students met Karin in her home. She was lying in bed wearing a long T-shirt, underwear, trousers and a scarf around her head. She had a stoma and a subcutaneous port- $a$ - cath. She had terminal cancer and was expected to die soon. The simulation room was decorated as a home with furniture, flowers, photos, candles and books. Karin lay in bed and, in some simulation sessions, her partner Petra/Peter, 28 years old (played by a student) sat next to her on the bed. She was in a lot of pain and worried about her son, Erik, 16 years old, who seemed to avoid visiting her. Her partner felt powerless and worried about their financial situation.

\section{Scenario 2}

In this scenario, Karin was alone and very tired. She had no appetite and sores in her mouth. She was worrying about the upcoming birthday of her daughter Olivia, 13 years old. Karin wanted to bake a cake as she would usually do, and she also wanted to be able to eat some cake, in order to give Olivia a good feeling about her 
birthday. In this scenario, Karin talked more about her concerns for the family and she asked what her final hours in life would be like.

\section{Scenario 3}

This scenario took place one week after the first scenario. Karin had died a few minutes before and her mother Eva was in the room next door. Eva had many questions and wondered about what would happen now with Karin's body, children, etc. Eva also had a lot of questions about what would happen now after Karin's death. Who would take care of the funeral? Who would tell the children that their mother has died? Who would call time of death?

\section{Post-simulation debriefing}

Directly after the third scenario had ended, the students met with their tutor in a meeting room. They sat down to debrief and discuss the simulation, how it went, and possible areas for improvement. The tutor guided the discussion and made sure to return to the learning goals of the simulation. Important learning areas to discuss included: end-of-life-care, ethics, maintaining a holistic approach, symptom and pain analysis, food and drink, family support, powerlessness, practical issues around the team, procedures of the death, the nursing process, keeping a professional approach in the home environment, other health care professionals and different religious views on death.

During the simulation, the PBL group tutor was present in the simulation room, but did not participate in the session or interact with the students. A post-simulation debriefing session was held directly after the simulation sessions. The tutor guided the discussions and the students were given the possibility to debrief and reflect on their own experiences of the simulation.

\section{Methods}

Ethnographic observations ${ }^{12,13}$ was carried out to describe the end-of-life care simulation in the context of nursing education. Approximately 60 students in eight group sessions with nursing students, taking part in an end-of-life care simulation were video- and audio recorded. The majority of the students were women between 20-30 years of age. The post- simulation 
debriefings when students reflected on the simulation were also audio-recorded. The collected data included a scenario template describing the setup of the simulations, field notes, audio and video recordings, and participant observations. The researchers $\mathrm{LH}$ and TJ took field notes while observing the video and audio recordings. LH also made participating observations during one simulation session and the post-simulation debriefing.

\section{Evaluation}

Predetermined questions guided the evaluation. In the evaluation of the video-recorded simulations, we aimed to describe the overall impression of the simulation, what topics the participants discussed, what issues they addressed, and their body language. In the evaluation of the debriefings, the aim was to describe our overall impression of the simulation, how the simulation worked as an educational method, what the students seemed to have learned, and how they felt about the simulation. To enhance trustworthiness in interpretations and conclusions, the researchers LH and TJ discussed the results until consensus was reached.

\section{Ethics}

All the students and tutors gave verbal consent to be video- and audio- recorded. They were informed about the confidential handling of the study data. Prior to the observations, the students received information, both orally and in writing, that they would not be graded or evaluated in the study. To deal with the students' psychological reactions and feelings that might happen as a result of the simulation, the students are asked to discuss their experiences in the post-debriefings, which can help them to process their feelings and emotions. Students who feel uneasy to actively participate in the simulation can take part as observers. 


\section{Findings}

To illustrate the experiences during the simulation, the three clinical scenarios and the final post-simulation debriefing will be described. The latter is mostly based on the students' and tutors’ narrative statements.

Pain and worries about the family

In scenario 1, most students were warm, reassuring, problem- solving, and keen to listen to what Karin said. They asked a lot of open questions in a reassuring manner and acted professionally. They were calm, sat down on the bed or on a chair next to Karin and sometimes held her hand. Some students were a bit uneasy at the beginning of the simulation. They were not prepared for talking to Karin as a manikin and acted a bit distant and nervous. However, after some time they became more relaxed and started to talk more freely with Karin. Some student-pairs seemed to find it difficult to contribute equally, while other pairs found this more natural.

In the conversation with Karin, the students asked how she felt and about her symptoms, such as pain. Some students asked actively about her pain medication or offered to increase the pain medication. If Karin indicated that she was worried or anxious, the students seem to hear her, but did not always take this further by asking more in-depth questions or addressing this adequately. With regard to worries about the stoma, students reassured Karin that the stoma did not smell and one student actually checked the stoma to see if everything was in working order.

With regard to the worries about the son, the students were very focused on finding practical solutions, such as offering to talk to the son, organize a family meeting, or involve a social worker. 
To some students, Karin also expressed feelings of guilt for being a burden to her family. The students told her that she should not feel like a burden and that the family surely would not have problems with that.

'You should not think like that, they are happy they can be there for you.'(student)

The birthday party

In scenario 2, the students were mostly warm, problem-solving, and engaged with Karin. They acted professionally, and sat next to her holding her hand. They asked many questions and tried to be there for Karin. The students asked about physical symptoms such as pain, fatigue and blisters in her mouth. They tried to find good solutions for Karin’s practical issues, such as how to help her take part in the baking of a birthday cake for her daughter's birthday.

'Maybe your partner could make the cake? '(student)

The students also made a lot of promises to Karin, e.g., that a professional could continue to support the children after she had died, that they could arrange for a wheelchair within a few hours, change her pain medication, order medication for the blistering in her mouth, etc.

Talking to the mother after the daughter had passed away

In the third scenario, the students first went to the room where Karin's body was situated and stayed in the room for a few moments. Some students checked if Karin really was dead (by checking her pulse). Some readjusted her sheets and then everyone left the room to sit in a room next door with Eva. Many students were compassionate and caring towards Eva. They asked her how she felt and tried to comfort her. 
They sat down with her at the table, some holding her hand. The person who played Eva was very emotional and tried to be realistic in her role as a grieving mother. She sometimes cried real tears, she spoke a lot and asked many questions about practical issues. The students tried to answer Eva's questions as best as they could, but it was clear that they lacked knowledge in this area. Several students promised Eva that they would find out more information and get back to her.

\section{The debriefing}

The post- simulation debriefing started with the tutor asking the students about their thoughts after the simulation. The students had a lot of thoughts and seemed very touched. Most of them were calm, but a few of them were upset and found it hard to discuss the simulation.

"I am terrified of death; I think it is very scary with dead people" (student)

Several of the students were not sure of Karin's time of death. Had she died recently or some days ago? Most students seemed to handle the situation in a good way even if the majority of them were not familiar with dealing with a dying person. Students who had experience of talking to dying patients seemed to be more comfortable in the simulation situation. The students reflected that they became emotional and touched, and acted as if they were taking care of a real person who was dying.

During the debriefing the students gave feedback and compliments to each other on how they had acted and talked during the simulation. The students were able to provide constructive feedback on positive observations. However, they seldom reflected on weak peer performance.

They stated that it was a good learning opportunity to watch and listen to each other on how to communicate during the simulation. 
"I was touched as I sat there observing the communication" (student)

"It was good to listen to how others talked (to Karin)." (student)

On several occasions, the students also referred back to what they had learnt during lectures on how to have good communication in challenging situations.

One crucial factor which seemed to make the simulation realistic was the environment in the simulation room. It was decorated as a home, and the students expressed that it was a totally different feeling going into the room compared to when they were doing other simulations, during which the room was decorated as a hospital room.

"It felt more real because of the environment. You come into somebody's home, someone is about to die, it feels familiar, perhaps from earlier were you have experienced similar situations." (student)

"There was time to think and reflect during the simulation, which made it feel more realistic.” (student)

Interacting with the manikin seemed natural to the students because the person who lent their voice to the manikin through a microphone sounded alive. However, at the same time it was hard for the students to talk to a "person” without having any eye contact or being able to observe facial expressions. One student remarked that it would have been better and more realistic if Karin had been played by an actor instead of a manikin.

The interaction with the mother Eva (played by an actor) was experienced as very positive by most students as she was a nice woman who was easy to talk to.

Even though it became more emotional to meet a real person, the students felt that this was a good opportunity to practice as it gave them a chance to experience this situation and their 
own emotions in a "safe” environment where no harm was done if they did not act professionally the whole time. Many students reflected that they found it stressful not being able to answer all of Eva's questions due to a lack of knowledge concerning the routines when somebody had died etc. Some students tried to be silent with Eva, aiming to give her some time to sit in silence for a while without talking. However, as there were almost always two students who interacted with Eva at the same time, some of them always started to talk. The students remarked that it would have been easier to discuss the situation alone with Eva, in order to have a chance to practice being silent in a communication situation.

"Practice more how to encounter a patient, not being afraid to listen to the patient's wishes and needs”. (student)

During the debriefing, the students further discussed how they had tried to comfort Karin in the best way. Several of the students remarked that it was an uncertain situation and that they did not know what would be brought up in the discussions with Karin. They also often returned to the practical issues that they were confronted with during the simulation, such as the palliative care they gave to Karin, including symptom relief, communication of present needs, their team-work, as well as the practical questions that were raised by Karin's mother and future bereavement support. Furthermore, they reflected on how they should have communicated about death in the best way to ensure that they met the patient's physical and existential needs. They realized that they might have missed talking about the patient's existential issues and focused the discussions on practical issues instead.

"Something I think all of us forgot to do was to ask Karin if she wanted to see a minister". (student)

The students discussed that sometimes it could be comforting enough to just hold the patient's hand and be present in the moment. They did not need to talk the whole time and they did not 
need to know the answers to all questions. Others pointed out that it was important to show an interest in the patient and share the patient's perspective.

The tutors sometimes provided short feedback to one or more of the students on how they had acted in the simulation.

“At one point you said (to Karin), 'do you want to talk more about your thoughts'? That was a very good thing to say". (tutor)

In this study, most of the tutors used different ways of supporting the students during the simulation and the debriefings, but on some occasions the tutors gave out too much information during the debriefing sessions and they focused too much on pointing out the learning goals of the simulation. This seemed to decrease the self-learning process which is vital in PBL and in the future the tutors need to let the students take the lead in the debriefings. However, in most sessions the tutors stayed in the background and allowed the students to take the lead of the discussions, starting with the students' own questions and thoughts. In the debriefings where the students were encouraged to take the lead, the whole group was more active in the discussions.

At the end of the debriefing session the tutor encouraged the students to reflect on their perceived learning needs after finishing the simulation. Many of the students felt that they lacked knowledge about routines in end-of-life care and stressed the importance of being prepared to answer practical questions from the patient and family members. Many students remarked that they needed to practice being silent in communication situations like the one in the simulation.

\section{Discussion}

When providing end-of-life care, nurses are expected to cope with the patient's and their family’s complex existential and emotional needs. In order to learn how to manage 
challenging dialogues it is important to provide nursing students with communication skills training, the opportunity to reflect on their own attitudes and feelings, and discuss what factors can have an impact on such conversations. ${ }^{14}$ The end-of-life care simulation presented in this study provided such a learning situation for the nursing students. The majority of the students found the simulation useful, they felt that it was realistic and they expressed that it was a good learning opportunity were they could practice how to handle challenging communicative situations with patients and family members. In addition, they also learned more about themselves and realized what thoughts they themselves had about death and dying. These findings are in line with previous research reporting on student's experiences of end-of-life care simulations. ${ }^{15,16}$

The goal of the simulation was described to the students as learning to communicate - "The good communication in challenging situations” - and caring for a dying person and their family members as well as learning about palliative care and theories about death and dying. However, students predominantly dealt with practical issues and showed dedication and creativity in order to solve practical problems. Many of them stressed the importance of more knowledge about the practical issues of end-of-life care. Issues relating to fear, anxiety and existential matters made the students feel less at ease. They seemed to hear what the patient said, but they did not really listen to what it meant. This is probably because most of the students were in an unfamiliar situation. It seemed easier for the students to focus on practical learning goals instead of, for example, communication techniques. When more existential issues were brought up, for example Karin's expressions of feelings of guilt being a burden to the family, many students had difficulties following the patient's emotional state. The students negated Karin’s feelings and made assumption about the family. Few of the students seemed to realize that they could not solve all problems and that sometimes it is essential to 'just be there' for the patient, without solutions. This shows a discomfort of the students in the 
situation, and it is important for the tutors to coach the students away from blandly reassuring replies that are not therapeutic. Additionally, the tutors could guide students into empowering Karin to solve her own issues about the birthday party. Maybe the students (with their inexperience) were 'trying to find good solutions, ' but tutors could be processing those feelings of 'fixing 'with the students.

In previous research it is acknowledged that there could be some physical limitations in endof-life care simulations as the manikin does not have the ability to show non-verbal communication, change temperature etc. ${ }^{17}$ This limitation was also found in this study, and it could be important to consider the possibility of using a real person instead of a manikin to eliminate these limitations and make the simulation even more realistic. This possibility was also expressed by some of the students in the debriefings. However, it is recognised that this could have logistical and financial consequences.

Previous research has shown that it is important to use simulated persons portraying family members in order to increase realism and add complexity to the simulation. ${ }^{6}$ It was also explicit in this study that the students appreciated having the opportunity to practice on how to support the mother (played by a simulated person), both in terms of her feelings of grief but also on how to handle practical issues.

Some students found it easier if they had talked alone with Karin and the mother instead of being there with a fellow student. If possible, it could be valuable to stage conversations in the simulation were the students could practice alone with Karin and the mother in order to enhance an even richer communication learning possibility.

The students in the observer roles expressed to have learnt a great deal during the simulations, even though they did not actively participate in the current simulation. This has also been found in other studies, where these students, who are not under pressure to "perform”, focus 
entirely on what is happening in the simulation. This provides them with a good learning situation while feeling less anxious. ${ }^{18}$

\section{Conclusions, future practice and research}

End-of-life care simulation can provide a successful and appreciated learning situation for nursing students, teaching them communication skills in challenging situations. At the same time it was obvious that the students found the simulation to be difficult and they lacked knowledge of end-of-life care and communication skills in order to meet all the needs of the patient and her family. The preparations before the simulation with readings, lectures and discussions in their tutorial group around the patient history might need to be strengthened from the faculty's side to support the students even more. Additional coaching from the tutors might help the students to focus more on communication and existential issues instead of mostly practical ones. One way of improving the support of the students is to improve the tutors' competencies, theoretical and practical knowledge about palliative care. The faculty have plans to bring in tutors who are nurses with a more vast experience and competence in palliative care to take part in the simulation sessions and the debriefings, to bring a greater knowledge of palliative care into the education. These tutors will possibly also find it easier to help the students to cope with psychosocial responses and processing of feelings.

The post-simulation debriefings are imperative for helping the students to reflect on their feelings, thoughts and responses after having performed the end-of-life care simulation, and it also enhances the learning process. ${ }^{3,6}$ In most of the groups the students were active in the debriefing discussions and shared their feelings and thoughts. The students themselves preferably lead the discussion in order to produce a meaningful group discussion and the tutor can stay in the background and intervene if needed. 
To further improve the simulation it could be of interest to evaluate the students' experiences of the simulation in the future. One possible way of doing that is to distribute a post simulation survey ${ }^{15}$ to the students after the simulation is finished and ask them to provide constructive feed-back of the set-up of the simulation, including preparations and readings, the scenarios and the tutors' support.

\section{Acknowledgements}

We thank all the students and tutors of Linköping University who participated in the study. 


\section{References}

1. Berragan L. Simulation: an effective pedagogical approach for nursing? Nurse Educ Today. 2011; 31(7):660-663.

2. Jeffries PR. Simulation in nursing education: From conceptualization to evaluation: National League for Nursing; 2012.

3. Medley CF, Horne C. Using simulation technology for undergraduate nursing education. J Nurs Educ. 2005; 44(1):31-34.

4. Lapkin S, Levett-Jones T, Bellchambers H, Fernandez R. Effectiveness of patient simulation manikins in teaching clinical reasoning skills to undergraduate nursing students: A systematic review. Clinical Simulation in Nursing. 2010; 6(6):e207-e222.

5. Cant RP, Cooper SJ. Simulation-based learning in nurse education: systematic review. Journal of advanced nursing. 2010; 66(1):3-15.

6. Gillan PC, van der Riet PJ, Jeong S. End of life care education, past and present: a review of the literature. Nurse education today. 2014; 34(3):331-342.

7. Johnson A, Chang E, O'Brien L. Nursing the dying: a descriptive survey of Australian undergraduate nursing curricula. International Journal of Nursing Practice. 2009; 15(5):417425.

8. IOM. Institute of Medicine. Dying in America: Improving quality and honoring individual preferences near the end of life. Washington, DC: The National Academies Press; 2015

9. Gillan PC, Jeong S, van der Riet PJ. End of life care simulation: A review of the literature. Nurse education today. 2014; 34(5):766-774.

10. Barrows HS. Problem-based learning: An approach to medical education: Springer Publishing Company; 1980.

11. Hård af Segerstad H, Helgesson M, Ringborg M, Svedin L. Problem-based learning, the tutor and the tutorial group. 1997.

12. Emerson RM, Fretz RI, Shaw LL. Writing ethnographic fieldnotes: University of Chicago Press; 2011.

13. Coffey A. The ethnographic self: Fieldwork and the representation of identity: Sage; 1999.

14. Strang S, Henoch I, Danielson E, Browall M, Melin-Johansson C. Communication about existential issues with patients close to death-nurses' reflections on content, process and meaning. Psycho-Oncology. 2014; 23(5):562-568.

15. Gillan PC, Parmenter G, van der Riet PJ, Jeong S. The experience of end of life care simulation at a rural Australian University. Nurse education today. 2013; 33(11):1435-1439.

16. Lippe MP, Becker H. Improving Attitudes and Perceived Competence in Caring for Dying Patients: An End-of-Life Simulation. Nursing education perspectives. 2015; 36(6):372-378.

17. Smith-Stoner M. Using high-fidelity simulation to educate nursing students about end-of-life care. Nursing Education Perspectives. 2009; 30(2):115-120.

18. Fluharty L, Hayes AS, Milgrom L, et al. A multisite, multi-academic track evaluation of end-oflife simulation for nursing education. Clinical Simulation in Nursing. 2012; 8(4):e135-e143. 
Table 1. Learning goals of the end-of-life care simulation

\begin{tabular}{|l|l|}
\hline Medical knowledge and competencies & \multicolumn{1}{c|}{ Communication } \\
\hline $\begin{array}{l}\text { Manage patients and their families } \\
\text { reactions to bad news in a } \\
\text { professional manner }\end{array}$ & $\begin{array}{l}\text { Apply a professional approach to } \\
\text { patients and families based on an } \\
\text { ethically reasoning }\end{array}$ \\
- $\begin{array}{l}\text { Assess and provide symptom } \\
\text { relieving care for patients with } \\
\text { partially or completely compensated } \\
\text { self-care needs when opportunities } \\
\text { for curative care are missing }\end{array}$ & - $\begin{array}{l}\text { Identify and consider the spiritual } \\
\text { and existential needs associated with } \\
\text { severe illness, dying and death and } \\
\text { reflect on own ethical views }\end{array}$ \\
$\begin{array}{l}\text { Apply a professional approach in } \\
\text { relation to patients, families and } \\
\text { other health care professionals }\end{array}$ & \\
\end{tabular}


Table 2. Overview of the scenarios and the debriefing

\begin{tabular}{|c|c|c|c|}
\hline $\begin{array}{l}\text { Pain and worries } \\
\text { about the family }\end{array}$ & The birthday party & $\begin{array}{l}\text { Talking to the } \\
\text { mother after the } \\
\text { daughter had } \\
\text { passed away }\end{array}$ & The debriefing \\
\hline $\begin{array}{l}\text { With regard to the } \\
\text { worries about the } \\
\text { son, the students } \\
\text { were very focused } \\
\text { on finding practical } \\
\text { solutions, such as } \\
\text { offering to talk to } \\
\text { the son, organize a } \\
\text { family meeting, or } \\
\text { involve a social } \\
\text { worker. }\end{array}$ & $\begin{array}{l}\text { The students tried to } \\
\text { find good solutions } \\
\text { for Karin's practical } \\
\text { issues, such as how } \\
\text { to help her take part } \\
\text { in the baking of a } \\
\text { birthday cake for her } \\
\text { daughter's birthday. } \\
\\
\text { 'Perhaps you can sit } \\
\text { in a wheelchair in } \\
\text { the kitchen while you } \\
\text { are helping out with } \\
\text { the baking?' } \\
\text { (student) 'Maybe } \\
\text { your partner could } \\
\text { make the } \\
\text { cake?'(student) }\end{array}$ & $\begin{array}{l}\text { Many students were } \\
\text { compassionate and } \\
\text { caring towards Eva. } \\
\text { They asked her how } \\
\text { she felt and tried to } \\
\text { comfort her. They } \\
\text { sat down with her at } \\
\text { the table, some } \\
\text { holding her hand. } \\
\text { 'How do you feel, if } \\
\text { we focus on you } \\
\text { know?' }\end{array}$ & $\begin{array}{l}\text { The students felt that } \\
\text { this was a good } \\
\text { opportunity to } \\
\text { practice to handle } \\
\text { end-of- life } \\
\text { situations as it gave } \\
\text { them a chance to } \\
\text { experience this } \\
\text { situation and their } \\
\text { own emotions in a } \\
\text { "safe” environment. } \\
\text { The interaction with } \\
\text { the mother Eva was } \\
\text { experienced as very } \\
\text { positive by most } \\
\text { students as she was a } \\
\text { nice woman who } \\
\text { was easy to talk to. } \\
\text { 'It was really great } \\
\text { to meet a real } \\
\text { person in this } \\
\text { simulation as it } \\
\text { made it much more } \\
\text { realistic.' (student) }\end{array}$ \\
\hline
\end{tabular}

